\title{
HUBUNGAN LAMA, TINDAKAN PENYEMPROTAN, DAN PERSONAL HY- GIENE DENGAN GEJALA KERACUNAN PESTISIDA
}

\author{
Related Long, Spraying Actions, And Personal Hygiene With Symptoms Of \\ Pesticide Poisoning \\ Herdianti \\ Program Studi Kesehatan Lingkungan STIKES Ibnu Sina Batam \\ Email: herdiantinyup@gmail.com
}

\begin{abstract}
ABSTRAK
Menurut World Health Organization (WHO), paling tidak 20.000 orang per tahun, mati akibat keracunan pestisida. Diperkirakan 5.000 - 10.000 orang per tahun mengalami dampak yang sangat fatal, seperti mengalami penyakit kanker, cacat tubuh, kemandulan dan penyakit liver. Penelitian ini menggunakan metode kuantitatif, dengan pendekatan cross sectional. Populasi dalam penelitian ini adalah semua petani nanas di Desa Tangkit Baru yaitu sebanyak 343 orang, dan dengan jumlah sampel penelitian sebanyak 75 orang (proportional random sampling). Instrumen penelitian yang digunakan adalah kuesioner. Hasil penelitian didapatkan analisa univariat bahwa dari 75 responden diketahui sebanyak $28(37,3 \%)$ responden yang mengalami gejala keracunan,19 (25,3\%) responden yang melakukan penyemprotan kurang baik (lama),48 (64,0\%) responden melakukan tindakan penyemprotan dengan baik dan sebanyak $48(64,0 \%)$ responden yang melakukan personal hygiene dengan baik. Analisa bivariat didapatkan nilai $p$-value $<0,05$ untuk variabel lama penyemprotan $(0,003)$, tindakan penyemprotan $(0,02)$, dan personal hygiene $(0,007)$. Terdapat hubungan yang bermakna antara variable masing-masing tersebut dengan gejala keracunan pestisida pada petani nanas di Desa Tangkit Baru.
\end{abstract}

Kata Kunci : : Lama, penyemprotan, hygiene, keracunan pestisida

\begin{abstract}
According to World Health Organization (WHO), minimum 20.000 people per year, died from pesticide poisoning. Estimated 5.000-10.000 people a year are affected very dangerous, like cancers, disablility, infertility and liver disease. This research uses quantitative method with cross sectional approach. Population in this research is pineapple farmers in the TangkitBaru village any 343 persons, and sample research is 75 persons (proportional random sampling). The research instrument is quesioner and paper of check list. Results obtained from univariateanalysis of 75 respondents that as many as $28(37,3 \%)$ respondents who experienced symptoms of poisoning pesticide, 19 (25,3\%) respondents too long in spraying pesticide, 48 $(64,0 \%)$ respondents who act poorly spraying and $48(64,0 \%)$ respondents who did good personal hygiene. Bivariate analysis to get $p$-value $<0,05$ to variable of long spraying $(0,003)$, act spraying $(0,02)$ and personal hygiene $(0,007$. There is a significant relationship between each variable with symptoms of poisoning pesticide in pineapple farmers at TangkitBaru Village.
\end{abstract}

Keywords : : Long, spraying, hygiene, poisoning of pesticide

\begin{tabular}{lll}
\hline Sekretariat & \multicolumn{2}{l}{ Article History: } \\
Editorial: Kampus FKM UNISMUH PALU - Palu 94118, & $\Rightarrow$ & Received 26 Maret 2018 \\
$\quad$ Sulawesi Tengah, Indonesia & $\Rightarrow$ & Revised 7 April 2018 \\
Telp/HP: +6281245936241, Fax (0451) 425627 & $\Rightarrow$ & Accepted 24 April 2018 \\
E-mail: jurnal.mppki@gmail.com & $\Rightarrow$ & Available online 25 Juni 2018 \\
OJS: http://jurnal.unismuhpalu.ac.id/index.php/PJKM & &
\end{tabular}




\section{PENDAHULUAN}

Beberapa faktor yang dapat mempengaruhi kondisi kesehatan dan daya kerja antara lain adalah faktor yang bersifat fisik, kimiawi, biologis, fisiologis dan mental psikologis yang terdapat dalam lingkungan kerja. Faktor-faktor tersebut yang intensitas nyamelampaui batas sehat pemaparan kerja (BSPK) mengakibatkan gangguan kesehatan dan daya kerja menurun, faktor-faktor yang dimaksud dapat berpengaruh baik terhadap kesehatan dan daya kerja pada komunitas (lahan pekerjaan) tenaga kerja yang bersangkutan (Suma'mur, 2013).

Kebiasaan petani dalam menggunakan pestisida kadang-kadang menyalahi aturan, selain dosis yang digunakan melebihi takaran, petani juga sering mencampur beberapa jenis pestisida, dengan alas an untuk meningkatkan daya racunnya pada hama tanaman. Tindakan yang demikian sebenarnya sangat merugikan, karena dapat menyebabkan semakin tinggi tingkat pencemaran pada lingkungan (Suma'mur, 2013).

Pestisida dalam bentuk gas merupakan pestisida yang paling berbahaya bagi pernafasan, sedangkan yang berbentuk cairan sangat berbahaya bagi kulit, karena dapat masuk ke dalam jaringan tubuh melalui ruang pori kulit. Menurut World Health Organization (WHO), paling tidak 20.000 orang per tahun, mati akibat keracunan pestisida. Diperkirakan 5.000 - 10.000 orang per tahun mengalami dampak yang sangat fatal, seperti mengalami penyakit kanker, cacat tubuh, kemandulan dan penyakit liver (Girsang Warlinson, 2009).

Salah satu masalah utama yang berkaitan dengan gejala keracunan pestisida adalah bahwa gejala dan tanda keracunan khususnya pestisida dari golongan organofosfat umumnya tidak spesifik bahkan cenderung menyerupai gejala penyakit biasa seperti pusing, mual dan lemah sehingga oleh masyarakat dianggap sebagai suatu penyakit yang tidak memerlukan terapi khusus. Menurut Gallo ada beberapa faktor yang mempengaruhi keracunan pesstisida antara lain dosis, toksisitas senyawa pestisida, lamanya terpapar pestisida dan jalan pestisida masuk dalam tubuh (Gallo M.A, 1991).
Faktor lain yang tidak kalah pentingdan sangat mempengaruhi terjadinya keracunan pestisida pada petani yaitukebersihan diri. Kebersihan diri atau personal hygiene mempunyai peranan yang cukup penting untuk upaya mencegah dampak negativ dari pemakaian pestisida pada petani. Petani yang menggunakan pestisida harus dipastikan terbebas dari residu pestisida yang mungkin menempel pada tubuh, pakaian atau peralatan petani lainnya.

\section{METODE PENELITIAN}

Penelitian ini merupakan penelitian kuantitatif dengan desain penelitian cross sectional yang bertujuan untuk mengetahui hubungan lama, tindakan penyemprotan dan personal hygiene dengan gejala keracunan pestisida pada petani nanas di Desa Tangkit Baru Kecamatan Sungai Gelam Kabupaten Muaro Jambi.

Populasi dalam penelitian ini adalah seluruh petani nanas di DesaTangkitBaru Kabupaten Muarojambi berjumlah 343 orang dengan teknik pengambilan sampel yaituproportional random sampling dengan jumlah sampel sebanyak 75 responden. Penelitian ini dilakukan pada 07 Juni sampai dengan 27 Juni 2016. Pengumpulan data dilakukan dengan pengisian kuesioner. Dan analisa data dilakukan secara univariat dan bivariat.

\section{HASIL}

Analisa Univariat

Berdasarkan tabel 1 (lampiran), menunjukkan bahwa pada 75 responden ada sebanyak $37,3 \%$ responden yang mengalami gejala keracunan, lama penyemrotan kurang baik $25,3 \%$, tindakan penyemprotan kurang baik ada $36,0 \%$ dan personal hygiene kurang baik $36,0 \%$.

\section{Analisa Bivariat}

Berdasarkan table 2 (lampiran), menunjukkan bahwa terdapat hubungan antara lama penyemprotan ( $p$-value $=0,003$ ), tindakan penyemprotan ( $\mathrm{p}$-value $=0,028$ ) dan personal hygiene ( $\mathrm{p}$-value $=0,007)$ dengan gejala keracunan pestisida pada petani nanas di Desa Tangkit Baru Kecamatan Sungai Gelam Kabupaten Muaro Jambi. 


\section{PEMBAHASAN}

Gambaran gejala keracunan pestisida, lama, tindakan penyemprotan dan personal hygiene.

Berdasarkan hasil penelitian di tabel 1 di dapatkan bahwa: dari 75 responden yang dijadikan sampel penelitian ada sebanyak 47 responden $(62,7 \%)$ yang tidak mengalami gejala keracunan pestisida dan 28 responden $(37,3 \%)$ yang mengalami gejala keracunan pestisida. Terdapat 56 responden $(74,7 \%)$ yang mempunyai kebiasaan lama penyemprotan yang baikdan 19 responden $(25,3 \%)$ yang kurangbaik. Terdapat 48 responden (64,0\%) yang mempunyaitindakanpenyemprotanbaikdan 25 responden $(36,0 \%)$ yang kurangbaik. Terdapat 48 $(64,0 \%)$ respondenyang mempunyai personal hygiene yang baik sisanya 25 responden $(36,0 \%)$ mempunyai personal hygiene kurang baik.

Pestisida adalah bahan kimia untuk membunuh hama, baik insekta, jamur maupun gulma, Sehingga pestisida dikelompokkan menjadi : Insektisida (pembunuh insekta), Fungisida (pembunuhjamur), dan Herbisida (pembunuh tanaman pengganggu/ gulma) (Depkes RI, 1992).

Banyak penelitian yang telah menunjukkan hubungan antara penggunaan pestisida dengan gangguan kesehatan yang diderita pekerja. Menurut WHO, keracunan pestisida baik yang disengaja maupun tidak disengaja merupakan masalah yang serius pada komunitas pertanian di Negara miskin dan berkembang. Diperkirakan sekitar 250.000 kematian terjadi karena keracunan pestisida setiap tahun (WHO, 2008).

Hasil penelitian menunjukkan bahwa istirahat minimal satu minggu dapat menaikkan aktivitas kholinesterase dalam darah pada petani penyemprot. Istirahat minimal satu minggu pada petani keracunan ringan dapat menaikkan aktivitas kholinesterase dalam darah menjadi normal $(87,50 \%)$. Sedangkan petani dengan keracunan sedang memerlukan waktu istirahat yang lebih lama untuk mencapai aktivitas kholinesterase normal.

Diantara tindakan penyemprotan yang baik, hendaknya petani melakukan penyemprotan lahan pertanian dengan mengikut iarah angin, memperhatikan suhu lingkungan saat akan melakukan penyempro- tan, melakukan prosedur penyimpanan pestisida yang tepat, penggunaan alat pelindung diri, dan mencampur larutan pestisida sesuai dengan dosis yang dianjurkan (Gallo M.A, 1991).

Hasil penelitian Halinda, 2005 menunjukkan bahwa untuk mencegah terjadinya keracunan pestisida pada petani beberapa hal yang harus menjadi perhatian selain dari tatalaksana penyemprotan adalah cara penyimpanan pestisida, cara mencampur pestisida dan cara membuang kemasan pestisida.

Hasil penilaian menunjukkan bahwa hampir seluruh variable penelitian bersifat positif dan hanya ada beberapa variabel yang hasilnya kurang baik misalnya variable gejala keracunan pestisida, dimana banyak responden yang mengalami gejala keracunan pestisida. Hal ini bias disebabkan karena rendahnya pemahaman responden dan kurangnya terpapar informasi berkenaan dampak penggunaan pestisida dalam kesehatan manusia dan lingkungan.

\section{Hubungan Lama Penyemprotan dengan Gejala Keracunan Pestisida pada Petani Nanas}

Berdasarkan tabel 2 (Lampiran), hasil uji statistik diperoleh nilai $\mathrm{p}$-value $0,003(<0,05)$, maka dapat disimpulkan ada perbedaan proporsi lama penyemprotan dengan gejala keracunan pestisida. Sehingga ada hubungan yang bermakna antara lama penyemprotan dengan gejala keracunan pestisida pada petani nanas di Desa Tangkit Baru Kecamatan Sungai Gelam Kabupaten Muaro Jambi.

Lamanya paparan pestisida pada keracunan pestisida organofosfat, kadangkadang blokade cholinesterase masih terjadi sampai 2-6 minggu. Paparan yang berlangsung terus-menerus lebih berbahaya daripada paparan yang terputus-putus pada waktu yang sama. Jadi pemaparan yang telah lewat perlu diperhatikan bila terjadi resiko pemaparan baru. Karena itu penyemprot yang terpapar berulang kali dan berlangsung lama dapat menimbulkan keracunan kronik (WHO, 2001).

Penelitian terkait dilakukan oleh Mahyuni, 2014 yang berjudul Faktor Resiko dalam Penggunaan Pestisida terhadap Keluhan Kesehatan pada Petani di kecamatan 
Berastagi kabupaten Karo menyatakan bahwa terdapat hubungan yang signifikan antara lama kerja dengan keluhan kesehatan yang dirasakan petani penyemprot pestisida dengan nilai $\mathrm{p}$-value $=0,002$.

Sebaiknya petani tidak memaksakan menyemprot lahan menggunakan pestisida lebih dari 3 jam. Jika memang setelah 3 jam penyemprotan belum selesai, maka sisa lahan pertanian yang belum disemprot dapat dilanjutkan esok harinya atau dengan menambah tenaga penyemprot untuk menyelesaikan penyemprotan tidak lebih dari 3 jam.

\section{Hubungan Tindakan Penyemprotan dengan Gejala Keracunan Pestisida pada Petani Nanas}

Berdasarkan tabel 2, hasil uji statistik diperoleh nilai p-value 0,028 $(<0,05)$, maka dapat disimpulkan bahwa ada perbedaan proporsi tindakan penyemprotan dengan gejala keracunan pestisida. Sehingga dapat disimpulkan ada hubungan yang bermakna antara tindakan penyemprotan dengan gejala keracunan pestisida pada petani nanas di Kecamatan Sungai Gelam Kabupaten Muaro Jambi.

Pestisida adalah bahan kimia untuk membunuh hama, baik insekta, jamurmaupun gulma, pestisida telah secara luas digunakan untuk tujuan memberantas hama dan penyakit tanaman dalam bidang pertanian. Pestisida juga digunakan dirumah tangga untuk memberantas nyamuk, kepinding, kecoa dan berbagai serangga pengganggu lainnya. Dilain pihak pestisida ini secara nyata banyak menimbulkan keracunan pada orang. Kematian yang disebabkan oleh keracunan pestisida jarang dilaporkan, hanya beberapa saja yang dipublikasikan terutama karena (untuk bunuh diri). Dewasa ini bermacam-macam jenis pestisida telah diproduksi dengan usaha mengurangi efek samping yang dapat menyebabkan berkurangnya daya toksisitas pada manusia, tetapi sangat toksik pada serangga (Depkes RI, 1992).

Penggunaan pestisida harus menggunakan 5 prinsip: 1). Penggunaannya dapat dilakukan bila populasi hama telah mencapai tingkat kerusakan atau ambang ekonomi. 2). Penggunaan pestisida yang berspektrum sempit mempunyai selektivi- tas tinggi dengan konsentrasi dosis yang tepat. 3). Penggunaan pestisida yang residunya pendek dan mudah terdekomposisi oleh faktor lingkungan. 4). Penggunaan pestisida pada saat hama berada pada titik terlemah. 5). Penggunaan pestisida bila cara pengendalian lain sudahtidak efektif dan efisien lagi (Rini, 2001).

\section{Hubungan Personal Hygiene dengan Gejala Keracunan Pestisida pada Petani Nanas.}

Berdasarkan tabel 2, hasil uji statistik diperoleh nilai $p$-value $0,007(<0,05)$, maka dapat disimpulkan bahwa ada perbedaan proporsi personal hygiene dengan gejala keracunan pestisida. Sehingga ada hubungan yang bermakna antara personal hygiene dengan gejala keracunan pestisida pada petani nanas di Kecamatan Sungai GelamMuaro Jambi.

Personal hygiene merupakan perawatan diri sendiri yang dilakukan untuk mempertahankan kesehatan baik secara fisik maupun psikologis (Alimul H, 2006). Dapat disimpulkan bahwa personal hygiene merupakan kegiatan atau tindakan membersihkan seluruh anggota tubuh yang bertujuan untuk memelihara kebersihan dan kesehatan seseorang.

Kebiasaan petani membersihkan alat penyemprotan di tempat sumber air bersih juga perlu di berikan pemahaman yang tepat. Karena hal ini dikuatirkan dapat membahayakan lingkungan, sumber air bersih dapat tercemar zat kimia yang berbahaya. Dampak dari tercemarnya lingkungan mungkin tidak akan langsung dirasakan, namun seiring dengan berjalannya waktu dan semakin besar jumlah kandungan pestisida pada sumber air bersih dan tanah, maka akan semakin memperbesar resiko terjadinya gangguan kesehatan akibat pencemaran lingkungan olehpestisida.

\section{KESIMPULAN DAN SARAN}

Penelitian ini menyimpulkan bahwa terdapat hubungan antara lama penyempro$\tan (\mathrm{p}$-value $=0,003)$, tindakan penyemprotan $(\mathrm{p}$-value $=0,028)$ dan personal hygiene $(\mathrm{p}$ value $=0,007$ ) dengan gejala keracunan pestisida pada petani nanas di Desa Tangkit Baru Kecamatan Sungai Gelam Kabupaten Muaro Jambi. 
Penelitian ini menyerankan pada pihak dinas kesehatan agar dapat berkoordinasi dengan seperti UPT pertanian untuk dapat meningkatkan upaya promotif tentang pencegahan terhadap keracunan pestisida pada petani nanas, antara lain dengan melakukan penyuluhan kesehatan dan simulasi tentang bagaimana melakukan penyemprotan pestisida yang tepat serta menghimbau agar petani dapat memeriksakan status kesehatan secara berkala ke fasilitas pelayanan kesehatan yang tersedia.

\section{DAFTAR PUSTAKA}

Alimul H. 2006. Kebutuhan Dasar Manusia. Penerbit Buku Kedokteran EGC : Jakarta

Depkes RI. 1992. Pengenalan dan Penatalaksanaan Keracunan Pestisida, SubditPengamanan Pestisida, Jakarta

Gallo M.A, Lwryk N.J. 1991. Organic Phosporus Pesticides dalam Handbook of Pesticide Toxicology,

Girsang Warlinson. 2009. Dampak negativ Penggunaan Pestisida. Universitas Simalungun Sumatera Utara. Penelitian Ilmiah.

Halinda Sari Lubis. 2005. Deteksi Dini dan Penatalaksanaan Pestisida Golongan Organofosfat pada tenaga kerja, FKM USU, Sumatera Utara.

Mahyuni Eka. 2014. Faktor Resiko dalam Penggunaan Pestisida terhadap Keluhan Kesehatan pada Petani di kecamatan Berastagi. USU : Medan

Rini. 2001. Petunjuk Penggunaan Pestisida, Penerbit Swadaya, Jakarta

Suma'mur. 2013. HIGIENE Perusahaan dan Kesehatan Kerja. Edisi 2. CV Sagung Seto. Jakarta

WHO. 2001.Organophosphorus Insectisides : A General Introduction

WHO. 2008. Prevention of Suicidal Behaviors: Feasibility Demonstration Project on Community Interventions for Safer Access to Pesticides, 2008. Diakses tanggal 20 Juni 2016. 


\section{LAMPIRAN}

Tabel 1. Distribusi Responden Berdasarkan Gejala Keracunan, Lama, Tindakan Penyemprotan dan Personal Hygiene pada Petani Nanas

\begin{tabular}{lcc}
\hline \multicolumn{1}{c}{ Variabel } & Frekuensi & $\mathbf{\%}$ \\
\hline $\begin{array}{l}\text { Gejala Keracunan Pestisida } \\
\text { Mengalami gejala keracunan } \\
\text { Tidak mengalami gejala keracunan }\end{array}$ & 28 & 37,3 \\
& & \\
Lama Penyemprotan & 47 & 62,7 \\
KurangBaik (>3 jam) & 19 & 25,3 \\
Baik (<3 jam) & 56 & 74,7 \\
TindakanPenyemprotan & & \\
KurangBaik & 27 & 36,0 \\
Baik & 48 & 64,0 \\
& & \\
Personal Hygiene & & 36,0 \\
KurangBaik & 27 & 64,0 \\
Baik & 48 & \\
\hline
\end{tabular}

Sumber: Data Primer 2016

Tabel 2. Distribusi Frekuensi Menurut Hubungan Berdasarkan Lama, Tindakan Penyemprotan dan Personal Hygiene dengan Gejala Keracunan pada Petani Nanas

\begin{tabular}{|c|c|c|c|c|c|c|c|c|}
\hline \multirow{3}{*}{ Variabel } & & \multicolumn{4}{|c|}{ Gejala Keracunan Pestisida } & \multicolumn{2}{|c|}{ Jumlah } & \multirow{3}{*}{$\begin{array}{c}\text { P- val- } \\
\text { ue }\end{array}$} \\
\hline & & \multicolumn{2}{|c|}{ Tidakmengalami } & \multicolumn{2}{|c|}{ Mengalami } & \multirow[t]{2}{*}{ Jml } & \multirow[t]{2}{*}{$\%$} & \\
\hline & & Jml & $\%$ & Jml & $\%$ & & & \\
\hline \multirow{2}{*}{$\begin{array}{l}\text { Lama } \\
\text { Penyempro } \\
\text { tan }\end{array}$} & Kurangbaik & 13 & 68,4 & 6 & 31,6 & 19 & 100 & \multirow[b]{2}{*}{0,003} \\
\hline & Baik & 15 & 26,8 & 41 & 73,2 & 56 & 100 & \\
\hline \multirow{2}{*}{$\begin{array}{l}\text { Tinda- } \\
\text { kanPenyem } \\
\text { protan }\end{array}$} & Kurangbaik & 15 & 55,6 & 12 & 44,4 & 27 & 100 & \multirow{2}{*}{0,028} \\
\hline & Baik & 13 & 27,1 & 35 & 72,9 & 48 & 100 & \\
\hline \multirow{2}{*}{$\begin{array}{l}\text { Personal } \\
\text { Hygiene }\end{array}$} & Kurangbaik & 16 & 59,3 & 11 & 40,7 & 27 & 100 & \multirow{2}{*}{0,007} \\
\hline & Baik & 12 & 25,0 & 36 & 75,0 & 48 & 100 & \\
\hline
\end{tabular}

Sumber: Data Primer 2016 